\title{
ANALYSIS OF PESTICIDE POISONING CASES IN A TERTIARY CARE HOSPITAL, MUMBAI.
}

\author{
Rajesh D. Kharat ${ }^{1}$, Rahul Kedare ${ }^{2}$ \\ ${ }^{1}$ Associate Professor, Department of Forensic Medicine, ${ }^{2}$ Assistant Professor, Department of Pharmacology, \\ MIMER Medical College, Talegaon Dabhade, Pune, India.
}

\begin{abstract}
Background: Acute pesticide poisoning (APP) is a serious problem worldwide. Pesticide poisoning is a common method of suicide attempt and less commonly accidental poisoning in India. Methods: A prospective analysis of pesticide poisoning cases admitted to the emergency department of tertiary care, teaching hospital. The data regarding sociodemographic profile, pattern of poisoning, Occupation, type of pesticide poisoning, relation of pesticide poisoning and risk factors, time of ingestion of pesticide poisoning and Seasonal variation were studied. Results: Of 174 cases admitted to the emergency department of hospital with a diagnosis of acute pesticide poisoning, the most cases observed in the age group 21-30 years (n: 72, 41.37\%). Total males affected were $94(54.02 \%)$ dominating the females 80 $(45.98 \%)$ and male to female ratio $(1.17: 1)$. But in younger age group, females were more affected than males. The maximum cases belonged to the lower socioeconomic class (n: 82, 47.12\%) and urban areas (n: 106, 60.91\%). Majority of the victims married and belonged to Hindu religion (n: 140, 80.4\%). The suicidal was commonest manner of pesticide poisoning accounting 98 cases $(56.32 \%)$. The occurrence of pesticide poisoning was more frequent in the evening (n: $82,47.12 \%$ ) and during the, monsoon (73, 41.95\%). Conclusion: Pesticide poisoning is responsible for great number of admissions and deaths in India. There is a need for adequate guidelines for sale, use, storage and safety practices for the pesticide. These will be helpful for the enhancement of the knowledge, awareness and safety practices among the population for prevention and reduction of the pesticide poisoning. It also emphasized on the early availability of treatment in the poisoning cases.
\end{abstract}

Keywords: Pesticide; Insecticide; Socio-demographic profile; Organophosphates.

\section{INTRODUCTION}

Pesticide or insecticide is any substance or mixture of substances intended for preventing, destroying, repelling or mitigating any pest. The identification of pesticide-related adverse health effects in the general population, consuming an inadvertent pesticide via food or water, is extremely difficult [1]. In parts of the developing world, pesticide poisoning causes more deaths than infectious diseases. Use of pesticides is poorly regulated and often dangerous; their easy availability also makes them a popular method of self-harm [2]. Pesticide poisoning is an important health problem particularly in the low-income countries like developing countries. There are about 3 million pesticide poisonings occurring worldwide annually as per WHO study [3]. Selfpoisoning with pesticides accounts for about a third of all suicides worldwide [4].

Most of the poisonings is due to the deliberate, intentional ingestion of the poison. Organophosphorus (OP) compounds occupy the greatest burden of poisoning related morbidity and mortality [5]. The distribution of poisoning varies in demographic areas and depends on availability and accessibility to the poison. The socioec-

DOI: $10.31878 / \mathrm{ijcb} .2018 .51 .04$
eISSN: $2395-0471$
iSSN: $2521-0394$

onomic, educational status and knowledge of pesticides also plays significant role in poisoning. Their improper proper usage and rapid industrialization have increased the incidence of poisoning. Insecticides poisoning are more frequent in India, as agriculture is the main occupation, and used to a greater extent [6].

The increasing trend of self-poisoning among young adults. The pesticides poisoning are frequent in India and other developing countries. The main reasons being agriculture based economies, poverty, and unsafe practices. Other significant factors are the illiteracy, ignorance and lack of protective clothing and easy availability of highly toxic pesticides [7]. The frequent application of pesticides in high concentrations pose serious health and financial risks to the farmers. The sales promotion activities and credit facilities promoted this irrational pesticide use. Harmful practices of spraying pesticides were due to the improper application of suggested protective actions suitable to regional condition and then lack of knowledge [8].

The meticulous data regarding pesticides (organophosphorus, organochlorine, carbamates, etc.) poisoning in different geographical areas will enhance prospect of early diagnosis and treatment. This will be useful for decreasing the mortality and morbidity rates with implementation of preventive guidelines. Information available in our region about pesticide poisoning is limited. The main objective of our study to find out the socio-demographic profile of pesticide poisoning in a tertiary care, teaching hospital, Mumbai, Maharashtra.

Correspondence: Dr Rahul Kedare, Department of Pharmacology, MIMER Medical College,

Talegaon Dabhade, Pune. E-mail: rahulkedare999@gmail.com

(C) Authors; 2019. International Journal of Clinical and Biomedical Research, Sumathi Publications.

This is an Open Access article which permits unrestricted non-commercial use, provided the original work is properly cited. 


\section{MATERIALS AND METHODS}

Study design: Descriptive study

Ethics approval: Study was approved by Institutional ethics committee of our college, from their relatives informed consent was obtained.

\section{Study duration: 1 Year (prospectively)}

Study location: A tertiary care, teaching hospital, Mumbai, Maharashtra.

Sampling method and sample size: Consecutive sampling method was used in the present study and sample size was 174 cases.

Inclusion criteria: The study included 174 cases of poisoning due to pesticide compounds. Exclusion criteria: Cases of snake bite, rat poisoning, insect bite, food poisoning and allergic reaction to drugs not included in the study.

Parameters studied: The data regarding sociodemographic profile, pattern of poisoning, Occupation, type of pesticide poisoning, relation of pesticide poisoning and risk factors, time of ingestion of pesticide poisoning and Seasonal variation were studied.

\section{RESULTS}

One hundred seventy-four cases admitted to the emergency department of our hospital with a diagnosis of acute pesticide poisoning. There is an increasing trend of poisoning with increase in age up to 30 years. The peak incidence in the age group of 21 - 30 years, which represented $72(41.37 \%)$ cases in this study (Table 1). Total male affected were $94(54.02 \%)$ dominating the female $80(45.98 \%)$ and male to female ratio (1.17:1). The pesticide poisoning is seen more in the female in the age group of 0-10 and 21-30 years as compared to male in respective groups. The eighty-four $(48.27 \%)$ victims married and remained unmarried, widower, widow and divorcee. The most of the victims were from Hindu religion (n: 140, 80.4\%) cases followed by Muslim $23(13.2 \%)$ cases. The maximum cases were from the urban area (n: 106, 60.91\%) as compared to the rural area (n: $68,39.08 \%$ ). In socioeconomic status, the most of the victims were from the lower class (n: 82, 47.12\%) followed by the lower middle class (n: 65, 37.35\%). Laborer, Hawker and workers in industries mills and shops (n: $39,22.41 \%$ ), were usual victims of pesticide poisoning (Table 2).

Table 1. Age-wise distribution

\begin{tabular}{l|l|l|l}
\hline Age (years) & Male & Female & N (\%) \\
\hline $00-10$ & 02 & 04 & $06(3.44)$ \\
\hline $11-20$ & 28 & 26 & $54(31.03)$ \\
\hline $21-30$ & 34 & 38 & $72(41.37)$ \\
\hline $31-40$ & 26 & 08 & $34(19.54)$ \\
\hline $41-50$ & 02 & 02 & $04(2.29)$ \\
\hline 51 \& above & 02 & 02 & $04(2.29)$ \\
\hline & & & 174 \\
\hline
\end{tabular}

Table 2. Occupation and pesticide poisoning

\begin{tabular}{l|l}
\hline Occupation & Number of cases \\
\hline Student & $26(14.94)$ \\
\hline Office goers / Professionals & $22(12.64)$ \\
\hline Businessman & $8(.04)$ \\
\hline $\begin{array}{l}\text { Laborer, Hawker, workers in- } \\
\text { dustries, mills, shops }\end{array}$ & $39(22.41)$ \\
\hline Farmer and agriculture workers & $27(15.51)$ \\
\hline Housewife & $31(17.81)$ \\
\hline Unemployed & $21(12.06)$ \\
\hline Total & $174(100)$ \\
\hline
\end{tabular}

Table 3. The relation of pesticide poisoning and risk factors

\begin{tabular}{l|l}
\hline Risk factors & N (\%) \\
\hline Chronic alcoholism & $10(5.75)$ \\
\hline Deliberate self-harm & $10(5.75)$ \\
\hline Psychiatric disorder & $08(4.6)$ \\
\hline Systemic disorder & $08(4.6)$ \\
\hline None & $138(79.3)$ \\
\hline
\end{tabular}

Table 4. The time of ingestion of pesticide poisoning.

\begin{tabular}{l|l}
\hline Time of ingestion & N (\%) \\
\hline $0600-1200$ hrs (morning) & $14(8.05)$ \\
\hline $1200-1800$ hrs (afternoon) & $60(34.48)$ \\
\hline $1800-2400$ hrs (evening) & $82(47.12)$ \\
\hline $2400-0600$ hrs (night) & $18(10.34)$ \\
\hline
\end{tabular}

Table 5. Seasonal variation

\begin{tabular}{l|l}
\hline Seasonal variation & N (\%) \\
\hline Monsoon (June-September) & $73(41.95)$ \\
\hline Winter (October-January) & $42(24.13)$ \\
\hline Summer (February-May) & $59(33.9)$ \\
\hline Total & 174 \\
\hline
\end{tabular}

The suicidal was commonest manner of pesticide poisoning accounting 98 cases $(56.32 \%)$, accidental (n: 68 , $39.08 \%$ ) and unknown (n: $8,4.59 \%$ ). There were no risk factors in 138 cases $(79.30 \%)$; the remaining cases presented with psychiatric disorders, chronic alcoholic, systemic disorder and deliberate self-harm (Table 3). The time of pesticide poisoning was maximum in the evening (n: $82,47.12 \%$ ) followed by afternoon (n: 60, $34.48 \%$ ) (Table 4). The most of the cases seen in monsoon $(73,41.95 \%)$, followed by summer $(59,33.90 \%)$ (Table 5). 


\section{DISCUSSION}

The amount of pesticide poisoning morbidity and mortality in a Society show the socio-demographic as well as the psychological stress of the Society and easy availability. Pesticide poisoning from intentional, accidental and occupational exposure is a significant problem in developing countries. In the present study, most of the cases were in the age group of 21-30 years. Acute pesticide poisoning commonly seen among laborers, Hawker, and workers. More cases reported due to intentional pesticide poisoning during, monsoon season and the evening time.

Our results were comparable to Peshin SS et al [9] who reviewed the data on telephone calls of pesticide poisoning in age ranged from 1 to 65 years. He observed, the predominance of males $(\mathrm{M}=62.19 \%, \mathrm{~F}=37.80 \%)$. The age group principally involved in poisoning $18-35$ years. The household pesticides calls were $59.38 \%$ and remaining for agricultural pesticides $(40.61 \%)$. The common manner of poisoning was intentional $(64.60 \%)$, accidental $(34.40 \%)$ and unknown (1\%). In household pesticides, the maximum cases were due to pyrethroids $(26.23 \%)$ followed by rodenticides $(17.06 \%)$ and organophosphates $(6.26 \%)$. Rao et al [10] studied patients admitted to the hospital with pesticide poisoning and revealed that two-thirds of the patients were $<30$ years old. Males affected were $57 \%$, and $96 \%$ had intentionally poisoned themselves, and his results were similar to our study.

Kora SA et al [11] reviewed, and 148 cases (63.8\%) were of OP poisoning out of 232 cases of poisoning. Males (n:65, 43.92\%) and females (n:83, $52.08 \%$ ), with a male to female ratio (1:1.27). Most of the cases were from the urban areas (n: $84,56.75 \%$ ), and they were educated and the illiterate people (50\% each). The married cases $(67 \%)$ was more than unmarried. The highest number of cases $(46.62 \%)$ seen in the age group of 21 to 30 years and housewives (n: $55,37.16 \%$ ) constituted majority of cases. The OP poisoning occurred mainly during the later part of the day $(43.92 \%)$, and no significant variation in the seasons. Though, Kora SA et al [11], and Padmanabha TS et al [12] studies are in organophosphate poisoning. Also, in our study, are organophosphate poisoning cases. Our results are similar to study results of Kora SA et al [11] except females were more than male.

In another study by Padmanabha TS et al [12] observed that, 285 cases $(63.8 \%)$ were of OP poisoning. Out of that, $215(76.42 \%)$ were males and $70(23.57 \%)$ were females. Most of the cases were from the rural areas (n: $275,96.49 \%$ ) than urban. The total percentage of OP poisoning cases with married status was $75.09 \%$. The highest number of cases $(41.05 \%)$ was from the age group of 21 to 30 years. Our results are comparable to study results of Padmanabha TS et al [12] except locality of the victims. The easy availability and ignorance about proper storage in household's pesticides could be mainly responsible for both suicidal and accidental. The younger age group, and women more affected stress, domestic violence, unemployment and behavioral problems. The low due to socioeconomic and laborer and workers are more affected due to rapid industrialization and groups psychological problems in the community.

\section{CONCLUSION}

The number of cases increasing every year and younger individuals being more affected. Comparatively, women are becoming vulnerable to pesticide poisoning at a younger age.

Suggestions: It is essential to make awareness and safety practices of pesticides in farms and household. The need of stringent legislature on the availability and marketing of the pesticides. The preventive measures like proper education guidelines, awareness programs and safety practices. The requirement of good treatment centres with analytical laboratories and information centers. The peripheral health centers need to be upgraded to manage the cases of pesticide poisoning in an emergency.

Conflict of Interest: There is no conflict of interest; the author does not have financial or other relationship with other people or organization that may inappropriately influence the author's work.

\section{REFERENCES}

1. Vij K. Textbook of Forensic Medicine and Toxicology: Principles and Practice, 6th ed. New Delhi: Elsevier India; 2014.p.495.

2. Eddleston M, Karalliedde L, Buckley N, Fernando R, Hutchinson G, Isbister G, et al., Pesticide poisoning in the developing world - a minimum pesticides list. Lancet. 2002; 360(9340):1163-7.

3. Moebus S, Bodeker W. Mortality of intentional and unintentional pesticide poisonings in Germany from 1980 to 2010. J Public Health Policy. 2015. doi: 10.1057/ jphp.2014.56.

4. Bertolote JM, Fleischmann A, Deaths from pesticide poisoning: a global response. The British Journal of Psychiatry. (2006) 189: 201-3.

5. Sheetu MKJ, Naik JD, Thakur MS, Langare SD, Pandey VO. Retrospective analysis of poisoning cases admitted in a tertiary care hospital. International journal of recent trends in science and technology. 2014;10(2):365-8.

6. Aaron R, Joseph A, Abraham S, Muliyil J, George K, Prasad J et al. Suicides in young people in rural southern India. Lancet. 2004; 363: 1117-8.

7. Thomas M, Anandan S, Kuruvilla P S, Singh P R, David S. Profile of hospital admission following acute poisoning experiences from a major teaching hospital in south India. Adverse drug reaction and toxicology review. 2000; 19:313-317.

8. Van Der Hoek W, Konradsen F, Athukorala K, Wanigadewa T. Pesticide poisoning: A major health problem in Sri Lanka. Social Science \& Medicine. 1998; 46(45):495-504.

9. Peshin SS, Srivastava A, Halder N, Gupta YK. Pesticide poisoning trend analysis of 13 years: A retrospective study based on telephone calls at the National Poisons Information Centre, All India Institute of Medical Sciences, New Delhi. J Forensic Leg Med. 2014; 22:57-61.

10. Rao CHS, Venkateswarlu V, Surender T, Eddleston M, Buckley NA. Pesticide Poisoning in South India - Opportunities for Prevention and Improved Medical Management. Trop Med Int Health. 2005; 10(6): 581-8.

11. Kora SA, Doddamani GB, Halagali GR, Vijayamahantesh SN, Boke U. Socio-demographic Profile of the Organophosphorus Poisoning Cases. Journal of Clinical and Diagnostic Research. 2011;5(5):953-6.

12. Padmanabha TS, Gumma K, Kulkarni GP. Study of profile of organophosphorus poisoning cases in a tertiary care hospital, north karnataka, bidar, india. International Journal of Pharma and Bio Sciences. 2014; 5(1):332 39. 